\title{
Perceptions of Victimhood and Entrepreneurial Tendencies
}

\author{
Yossi Maaravi**, Boaz Hameiri² and Tamar Gur ${ }^{3,4}$ \\ 'The Adelson School of Entrepreneurship, Reichman University, Herzliya, Israel, ${ }^{2}$ The Evens Program in Conflict Resolution \\ and Mediation, Gershon H. Gordon Faculty of Social Sciences, Tel Aviv University, Tel Aviv, Israel, ${ }^{3}$ Department of \\ Psychology, The Hebrew University of Jerusalem, Jerusalem, Israel, ${ }^{4}$ Baruch Ivcher School of Psychology, Reichman \\ University, Herzliya, Israel
}

\section{OPEN ACCESS}

Edited by:

Karen Moustafa Leonard, University of Arkansas at Little Rock,

United States

Reviewed by:

Eduardo Moraes Sarmento, Lusophone University of Humanities and Technologies, Portugal Majid Murad, Jiangsu University, China

*Correspondence: Yossi Maaravi myossi@idc.ac.il

Specialty section: This article was submitted to Personality and Social Psychology, a section of the journal Frontiers in Psychology

Received: 19 October 2021

Accepted: 06 January 2022

Published: 14 February 2022

Citation: Maaravi Y, Hameiri B and Gur T (2022) Perceptions of Victimhood

and Entrepreneurial Tendencies.

Front. Psychol. 13:797787. doi: 10.3389/fpsyg.2022.797787
There is a growing scientific interest around entrepreneurship. One central line of research examines how different personality traits and characteristics such as creativity or resilience relate to entrepreneurial intentions and behavior. In the current research, we add to this literature by focusing on trait victimhood, a trait that entrepreneurship research has overlooked and may be relevant to understanding entrepreneurial tendencies. In two studies in Israel among a sample of entrepreneurship students (Study 1) and a sample representing the general public (Study 2), we show that trait victimhood is negatively related to entrepreneurial personality (Study 1) and behavior (Study 2). Moreover, Study 2 suggests that a strong sense of self-efficacy may buffer against trait victimhood's adverse effects on behavioral entrepreneurship.

Keywords: victimhood, entrepreneurship, entrepreneurial personality, entrepreneurial tendencies, entrepreneurial intentions, self-efficacy

\section{INTRODUCTION}

In the 21 st century, the entrepreneurial approach is becoming central for individuals, organizations, and even nations (Kuratko, 2009; Jackson, 2011; Mozaffary, 2020). Hence, there is growing scientific research in entrepreneurship, with one line being entrepreneurial personality (Brandstätter, 2011; Obschonka et al., 2019). Entrepreneurial personality was recently characterized by: self-efficacy, autonomy, innovativeness, internal locus of control, achievement motivation, optimism, stress tolerance, and risk-taking (Cuesta et al., 2018; Gielnik et al., 2020), highlighting the role of internal locus of control and self-efficacy beliefs processes (Lüthje and Franke, 2003; Naushad and Malik, 2018). In the current research, we aim to contribute to this literature by exploring the relationship between entrepreneurship and trait victimhood (Gabay et al., 2020a,b), which was overlooked in this context and may be highly relevant to understanding entrepreneurial tendencies.

Trait victimhood is defined as "an ongoing feeling that the self is a victim... generalized across many relationships, such that victimization becomes a central part of the individual's identity." (Gabay et al., 2020a, p. 361). It fundamentally affects emotions, cognitions, and behaviors (Gabay et al., 2020b). We argue that trait victimhood is particularly conducive for the research on entrepreneurship because it provides a parsimonious conceptualization and measure, which is theoretically associated with several factors of entrepreneurial intent and behavior (Lüthje and Franke, 2003). Specifically, we argue that trait victimhood may be associated with an external locus of control (Gabay et al., 2020b) and higher perceived barriers. This is because people 
high in victimhood are more likely to be hyper-sensitive and expect hurtful behaviors and untrustworthiness by malevolent others in their daily lives (Gollwitzer et al., 2013).

Thus, in the current research, we explore the potential association between entrepreneurial tendencies and trait victimhood. Despite this research's exploratory nature, we reasoned that trait victimhood would be negatively associated with entrepreneurship. For the conceptual model noting the researchers' expectations see Figure 1. We examined the association between trait victimhood and entrepreneurship in two studies. These studies were conducted among a sample of entrepreneurship undergraduate students in Israel (Study 1) and an online sample drawn from the general population of adults in Israel (Study 2).

\section{STUDY 1}

\section{Method}

\section{Participants and Procedure}

We sampled 208 entrepreneurship undergraduate students at a private university in Israel $\left(40.9 \%\right.$ women; $M_{\text {age }}=23.74$, $\mathrm{SD}=2.19$ ) that received course credits in exchange for their participation. Participants responded to an online questionnaire with the measures detailed below, following which they reported their socio-demographic information. Unless indicated otherwise, all items in both studies were rated on a 7-point Likerttype scale ranging from (1) "strongly disagree" to (7) "strongly agree” (for complete information, see Supplementary Material).

\section{Measures}

Trait victimhood was assessed with an abridged 9-item version of the tendency for interpersonal victimhood scale (Gabay et al., 2020 b; e.g., "It is important to me that people who hurt me acknowledge that an injustice has been done to me"; $\alpha=0.73$ ).

Enterprising Tendency was assessed with the 54-item GET2 test (Caird, 2006) on a dichotomous scale anchored at (0) "disagree" and (1) "agree" (e.g., "At work, I often take over projects and steer them my way without worrying about what other people think"), which were summed to obtain the GET2 score $(\alpha=0.65)$.

Behavioral Entrepreneurship was assessed by asking participants to report whether they founded at least one business initiative in the past (29.8\% of the sample reported that they did).

\section{Results and Discussion}

For variable means, SDs and correlations see Table 1 . Looking at the simple bivariate correlations, trait victimhood was significantly negatively correlated with enterprising tendency, but not with behavioral entrepreneurship. These associations did not meaningfully change when we controlled for participants' age and gender.

While a moderate association was found between enterprising tendency and behavioral entrepreneurship, trait victimhood was unexpectedly not associated with behavioral entrepreneurship. Possibly we have not been able to detect this effect due to the current study's limitations. Specifically, the sample in Study 1 was comprised of entrepreneurship students, which does not represent the general public. Indeed, it yielded a remarkably lower trait victimhood mean score $(M=3.53, \mathrm{SD}=0.91)$ compared to other studies conducted in Israel (Gabay et al., 2020b) and in the United States (Hameiri et al., 2020), where means were around or above the scale's midpoint (4).

Another potential explanation for the lack of the above association might be the result of a moderating agent. Previous work has established the pivotal role of self-efficacy, i.e., "beliefs in one's capabilities to mobilize the motivation, cognitive resources, and courses of action needed to meet given situational demands" (Wood and Bandura, 1989, p. 408), plays in entrepreneurial intent and behavior (Singh, 1978; Naushad and Malik, 2018). Thus, while individuals might have an enterprising tendency, actual engagement in entrepreneurship also depends on their beliefs of pursuing and succeeding despite possible difficulties (Chen et al., 1998).

In Study 2, we addressed the methodological limitation by sampling participants representing the general population in Israel. Furthermore, we introduced a measure of global self-efficacy (GSE) to examine whether it moderated the relationship between trait victimhood and (self-reported) behavioral entrepreneurship. Self-efficacy measures during entrepreneurship training were recently associated with business ownership (Gielnik et al., 2020). We reasoned that those who think they can get their initiatives off the ground would generally show high behavioral entrepreneurship levels, irrespective of their level of trait victimhood. In contrast, those who believe that they are less efficacious would be more affected by their tendency for victimhood. The model was revised accordingly to entail GSE and the components of the initial model (see Figure 2).

\section{STUDY 2}

\section{Method}

\section{Participants and Procedure}

We sampled 354 Jewish-Israelis (48.6\% women; $M_{\text {age }}=41.71$, $\mathrm{SD}=16.02$ ) to participate in an online study via an Israeli survey company (Midgam Project). Participants responded to measures detailed below and provided some socio-demographic information. ${ }^{1}$

\section{Measures}

Trait victimhood $(\alpha=0.82)$ was measured with the same items as in Study 1.

Global Self-Efficacy was measured with the 10-item GSE scale (Schwarzer et al., 1999; e.g., "I can always manage to solve difficult problems if I try hard enough"; $\alpha=0.91$ ).

Behavioral Entrepreneurship was measured with the same item as Study 1. We added three more items asking participants to indicate whether they are currently self-employed, are planning to become self-employed in the foreseeable future, and whether they founded any social initiatives. Participants' score was

\footnotetext{
${ }^{1}$ This was part of a larger study that included other variables that were published in a separate paper (for further details see Supplementary Material).
} 


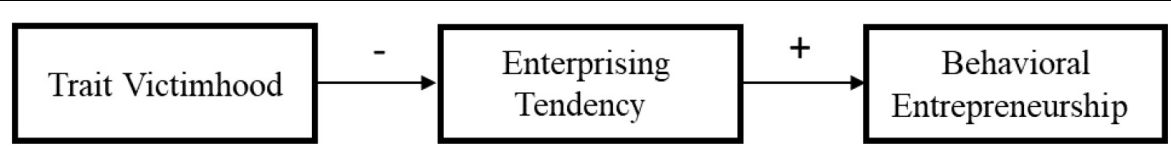

FIGURE 1 | Conceptual model for trait victimhood and entrepreneurship.

TABLE 1 | Means, SDs, and correlations of study variables (Studies 1 and 2).

\begin{tabular}{|c|c|c|c|c|c|c|}
\hline & Mean (SD) & 1 & 2 & 3 & 4 & 5 \\
\hline \multicolumn{7}{|l|}{ Study 1} \\
\hline Trait victimhood & 3.53(0.91) & - & & & & \\
\hline Enterprising tendency & $37.92(4.84)$ & $-0.22^{\star \star}$ & - & & & \\
\hline Behavioral entrepreneurship $(0=N, 1=Y)$ & - & -0.10 & $0.29^{\star \star}$ & - & & \\
\hline Age & 23.74(2.19) & 0.02 & -0.03 & 0.12 & - & \\
\hline Gender (1 = M, 2 = F) & - & -0.06 & -0.02 & -0.07 & $-0.24^{\star \star}$ & - \\
\hline \multicolumn{7}{|l|}{ Study 2} \\
\hline Trait victimhood & 4.54(0.99) & - & & & & \\
\hline Global self-efficacy & $5.33(0.85)$ & $0.14^{\star \star}$ & - & & & \\
\hline Behavioral entrepreneurship $(0=N, 1=Y)$ & - & -0.02 & $0.17^{\star \star}$ & - & & \\
\hline Age & $41.71(16.02)$ & 0.003 & 0.01 & -0.08 & - & \\
\hline Gender $(1=\mathrm{M}, 2=\mathrm{F})$ & - & 0.09 & 0.04 & -0.10 & 0.02 & - \\
\hline
\end{tabular}

computed such that those who responded "yes" on any of these four items received 1 (52.3\% of the sample), and those who answered "no" on all items received 0.

\section{Results and Discussion}

For means, SDs and correlations, see Table 1. Looking at the simple bivariate correlations, trait victimhood was not correlated with behavioral entrepreneurship. Interestingly, trait victimhood was positively correlated with GSE. Predictably, GSE was positively correlated with behavioral entrepreneurship. We tested the trait victimhood $\times$ GSE interaction on behavioral entrepreneurship, using Hayes's (2018) PROCESS (Model 1) bootstrapping command with 5,000 iterations. Similar to Study 1 , trait victimhood did not significantly predict behavioral entrepreneurship $[b=-0.15, s e=0.12, p=0.201,95 \%$ Confidence Interval $(\mathrm{CI})=(-0.38,0.08)]$; while GSE did $[b=0.49$, se $=0.14$, $p<0.001,95 \% \mathrm{CI}=(0.22,0.76)]$. More importantly, the analysis yielded a significant interaction $[b=0.29$, se $=0.13, p=0.027$, $95 \% \mathrm{CI}=(0.03,0.55)$; see Figure $3 \mathrm{]}$. Conditional effects revealed that trait victimhood was significantly negatively associated with behavioral entrepreneurship among the low-GSE participants $[b=-0.40, s e=0.18, p=0.029,95 \% \mathrm{CI}=(-0.76,-0.04)]$, but not among the high-GSE participants $[b=0.10$, se $=0.14, p=0.471$, $95 \% \mathrm{CI}=(-0.17,0.38)]$. These effects hold when controlling for age and gender.

Finally, we included several measures to replicate Lüthje and Franke's (2003) entrepreneurial intent model. While they were not reliable $(\alpha s<0.62)$, and were omitted from the final analysis, correlations between trait victimhood and individual items from these measures provide additional tentative corroboration for our reasoning. Specifically, trait victimhood was positively correlated with both locus of control items (e.g., "I often feel that that's how things are and there's nothing I can do about it"; $r s>0.21$, ps $<0.001$ ), and with all three perceived barriers items (e.g., "State laws are adverse to running a company"; $r s>0.15$, ps $<0.004)$.

\section{GENERAL DISCUSSION}

It seems that there is consensus around the "entrepreneurial imperative of the twenty-first century" (Kuratko, 2009), which also led to flourishing scientific research around its different aspects-including a specific focus on the personality traits (or lack thereof) that characterize entrepreneurs. The present research explored the association between trait victimhood and entrepreneurship. While potentially a parsimonious conceptual and empirical construct in entrepreneurship, trait victimhood was overlooked in this context. Indeed, in two studies among either a sample of Israeli entrepreneurship students or a sample representing the Jewish-Israeli general public, trait victimhood is inversely related to entrepreneurial personality and behavior. Furthermore, having a strong sense of self-efficacy buffers against trait victimhood's adverse effects on behavioral entrepreneurship.

\section{Theoretical and Practical Implications}

This research has several important theoretical and practical implications. First, the research on trait victimhood has explored how it shapes people's emotions, cognition, and behavior. Two recent examples are people's willingness to forgive those who hurt them and seek revenge (Gabay et al., 2020b) and adherence to health guidelines in the COVID-19 pandemic 


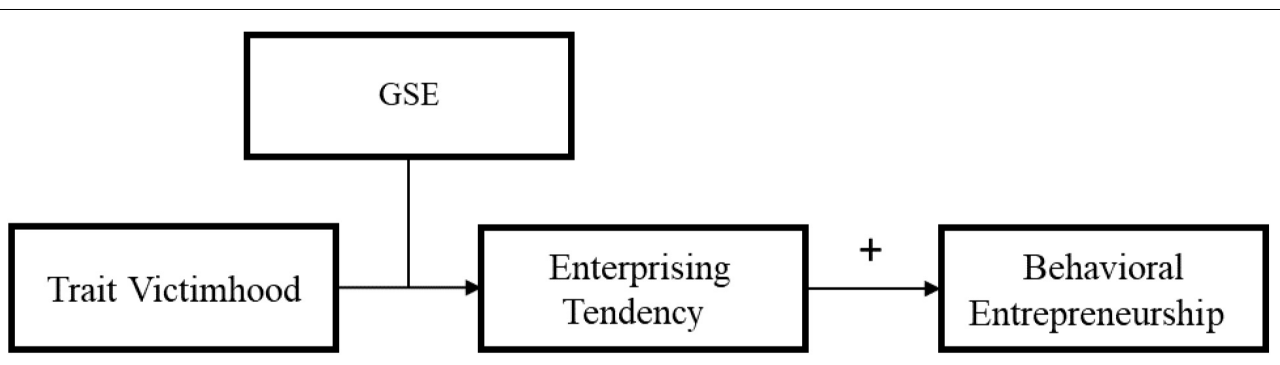

FIGURE 2 | The revised conceptual model for trait victimhood and entrepreneurship.

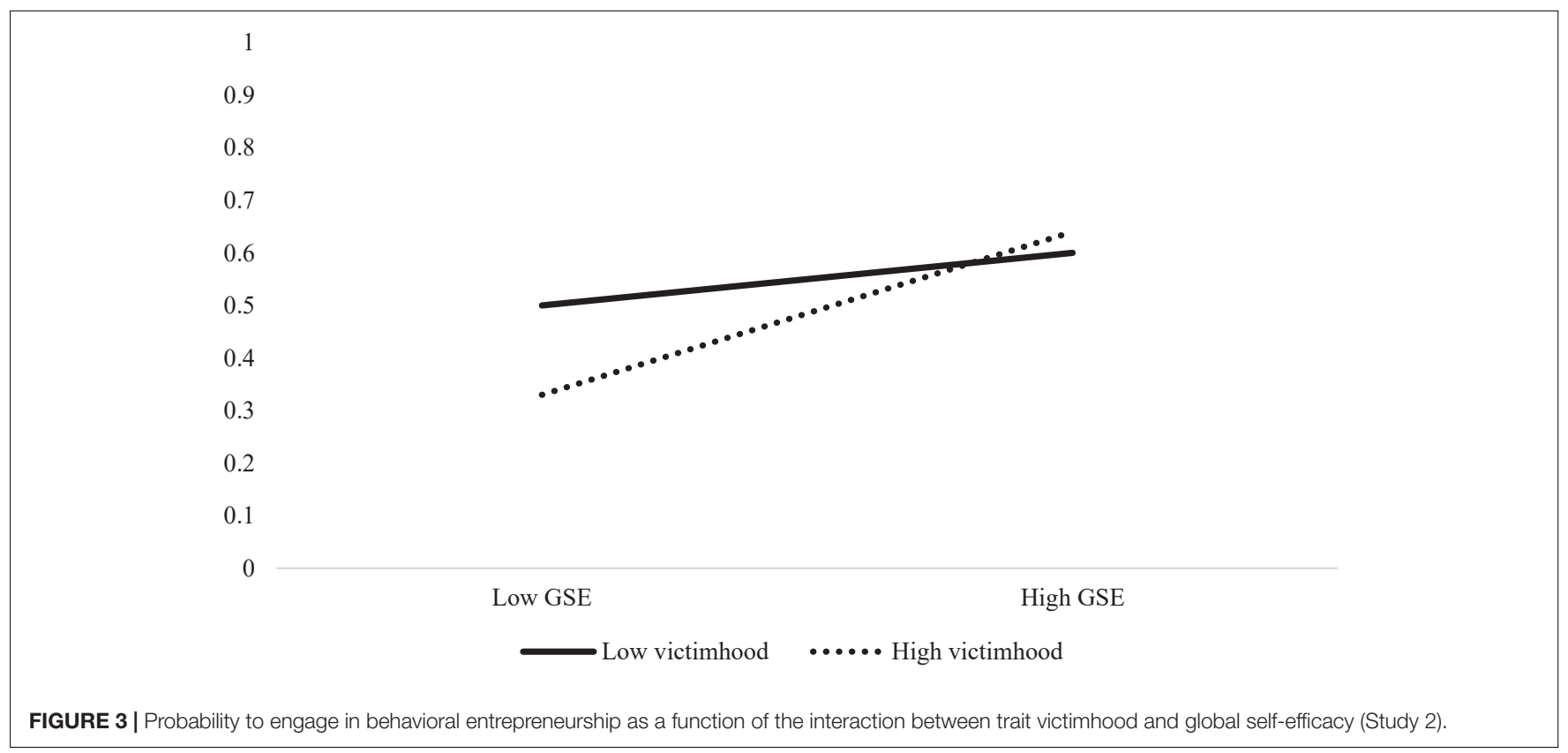

(Maaravi et al., 2020a). To the best of our knowledge, the current study is the first to show that trait victimhood might also be associated with people's career choices or their ability to succeed as entrepreneurs. Correspondingly, levels of trait victimhood were significantly lower among the sample of entrepreneurship undergraduate students in Study $1(M=3.53, \mathrm{SD}=0.91)$ than in the sample that resembled the Jewish population in Israel in Study $2(M=4.54, \mathrm{SD}=0.99 ; p<0.001)$ and compared to previous studies conducted in Israel and the United States (Gabay et al., 2020b; Hameiri et al., 2020; Maaravi et al., 2020a).

Furthermore, the current research adds to our understanding of the psychology of entrepreneurship. As part of the natureversus-nurture debate of entrepreneurship, some scholars argue that entrepreneurship can be taught or at the very least encouraged (Maaravi et al., 2020b). The current research suggests that high trait victimhood individuals are less likely to benefit from such endeavors. However, one way to circumvent this potential barrier is by bolstering aspiring entrepreneurs' selfefficacy (e.g., Naushad and Malik, 2018).

These last implications bear theoretical and significant practical importance since self-efficacy is highly affected by environmental cues. It can be induced via peer modeling (exposure to peers who successfully ventured) and persuasion (speaking to the person of their competence; Dale and Barry, 2007). However, all these intriguing avenues should be thoroughly examined in future research.

\section{Limitations and Future Research}

Beyond the below limitations, there are no specific "Limitations on Generality" (Simons et al., 2017), such as specific populations or specific experimental materials. However, it should be noted that the current research is correlational. Thus, we cannot decisively conclude that trait victimhood or GSE had a causal effect on entrepreneurial behavior. Future research should attempt to establish causality by, for example, priming a sense of victimhood. However, our hypothesized independent variables were personality traits, which should precede and predict behavior. Another limitation is that, albeit each study utilized a different sample, both studies were conducted with Jewish-Israeli participants. Thus, it is important to replicate these findings in other contexts. 


\section{CONCLUSION}

To summarize, we argue that trait victimhood offers a simple yet powerful measure of individual differences when facing challenges and hardships, which are the reality of entrepreneurship and the creative process. We also present a likely moderator that may bolster people against the effects of trait victimhood.

\section{DATA AVAILABILITY STATEMENT}

The data that support the findings of this study are openly available at https://osf.io/7e69t/?view_only= 91d5c2db4b1346cd8db2a549fbf42bc6.

\section{ETHICS STATEMENT}

The studies involving human participants were reviewed and approved by the Adelson School of Entrepreneurship Ethics

\section{REFERENCES}

Brandstätter, H. (2011). Personality aspects of entrepreneurship: A look at five meta-analyses. Personal. Indiv. Diff. 51, 222-230. doi: 10.1016/j.paid.2010.07. 007

Caird, S. (2006). “General measure of enterprising tendency version 2 (GET2)," in Entrepreneurship and innovation, ed. T. Mazzarol (Melbourne: Tilde University Press), 247-266.

Chen, C. C., Greene, P. G., and Crick, A. (1998). Does entrepreneurial selfefficacy distinguish entrepreneurs from managers? J. Bus. Vent. 13, 295-316. doi: 10.1016/S0883-9026(97)00029-3

Cuesta, M., Suárez-Álvarez, J., Lozano, L. M., García-Cueto, E., and Muñiz, J. (2018). Assessment of eight entrepreneurial personality dimensions: validity evidence of the BEPE battery. Front. Psychol. 9:2352.

Dale, H. and Barry, J. Z. (2007). Influencing Children's Self Efficacy and SelfRegulation of Reading and Writing Through Modeling. Read. Writ. Q. 23, 7-25. doi: 10.1080/10573560600837578

Gabay, R., Hameiri, B., Rubel-Lifschitz, T., and Nadler, A. (2020a). "The tendency to feel victimized in interpersonal and intergroup relationships," in The social psychology of collective victimhood, ed. J. R. Vollhardt (Oxford: Oxford University Press), 361-378. doi: 10.1093/oso/9780190875190.003.0017

Gabay, R., Hameiri, B., Rubel-Lifschitz, T., and Nadler, A. (2020b). The tendency for interpersonal victimhood: the personality construct and its consequences. Personal. Indiv. Diff. 165:110134. doi: 10.1016/j.paid.2020.110134

Gielnik, M. M., Bledow, R., and Stark, M. S. (2020). A dynamic account of selfefficacy in entrepreneurship. J. Appl. Psychol. 105:487. doi: 10.1037/apl0000451

Gollwitzer, M., Rothmund, T., and Süssenbach, P. (2013). The sensitivity to mean intentions (SeMI) model: Basic assumptions, recent findings, and potential avenues for future research. Soc. Person. Psychol. Comp. 7, 415-426. doi: 10. $1111 /$ spc3.12041

Hameiri,B., Moore-Berg, S. L., Guillard, C., Falk, E., and Bruneau, E. G. (2020). Perceived victimhood shapes support for political violence. Manuscript submitted for publication.

Hayes, A. F. (2018). Introduction to mediation, moderation, and conditional process analysis: A regression-based approach, 2nd Edn. New York, NY: Guilford Press.

Jackson, C. J. (2011). How sensation seeking provides a common basis for functional and dysfunctional outcomes. J. Res. Personal. 45, 29-36. doi: 10.1016/ j.jrp.2010.11.005

Kuratko, D. F. (2009). The entrepreneurial imperative of the 21 th century. Business Horizons 52, 421-428. doi: 10.1016/j.bushor.2009.04.006

Lüthje, C., and Franke, N. (2003). The 'making' of an entrepreneur: Testing a model of entrepreneurial intent among engineering students at MIT. R\&D Manag. 33, 135-147.
Committee as part of the Institutional Review Board (IRB), IDC Herzliya. The patients/participants provided their written informed consent to participate in this study.

\section{AUTHOR CONTRIBUTIONS}

YM: study conceptualization, project management, data collection, and report writing. $\mathrm{BH}$ : study conceptualization, data collection, data preparation, data analysis, and report writing. TG: data collection, data preparation, data analysis, and report writing. All authors contributed to the article and approved the submitted version.

\section{SUPPLEMENTARY MATERIAL}

The Supplementary Material for this article can be found online at: https://www.frontiersin.org/articles/10.3389/fpsyg. 2022.797787/full\#supplementary-material

Maaravi, Y., Hameiri, B., and Gur, T. (2020a). Fighting coronavirus one personality at a time: Need for structure, trait victimhood and adherence to COVID-19 health guidelines. Front. Psychol. 11:576450. doi: 10.3389/fpsyg.2020.576450

Maaravi, Y., Heller, B., Amar, S., and Stav, H. (2020b). Training techniques for entrepreneurial value creation. Entrep. Educ. 3, 215-238. doi: 10.1007/s41959020-00028- 2

Mozaffary, M. (2020). The Importance of Following An Entrepreneurial Approach In Media Firms. J. Org. Cult. Comm. Conflict 24, 1-2. doi: 10.4135/ 9781446211380.n1

Naushad, M., and Malik, S. A. (2018). The mediating effect of entrepreneurial selfefficacy in entrepreneurial intention-a study in Saudi Arabian context. Probl. Perspect. Manag. 16, 267-275. doi: 10.21511/ppm.16(1).2018.26

Obschonka, M., Moeller, J., and Goethner, M. (2019). Entrepreneurial passion and personality: the case of academic entrepreneurship.Front. Psychol. 9:2697. doi: 10.3389/fpsyg.2018.02697

Schwarzer, R., Mueller, J., and Greenglass, E. (1999). Assessment of perceived general self-efficacy on the Internet: Data collection in cyberspace. Anxiet. Stress Coping 12, 145-161.doi: 10.1080/10615809908248327

Simons, D. J., Shoda, Y., and Lindsay, D. S. (2017). Constraints on generality (COG): a proposed addition to all empirical papers. Persp. Psycholog. Sci. 12, 1123-1128. doi: 10.1177/1745691617708630

Singh, S. (1978). Achievement motivation and entrepreneurial success: a follow-up study. J. Res. Personal. 12, 500-503.doi: 10.1016/0092-6566(78)90075-2

Wood, R., and Bandura, A. (1989). Impact of conceptions of ability on selfregulatory mechanisms and complex decision making. J. Personal. Soc. Psychol. 56:407. doi: 10.1037/0022-3514.56.3.407

Conflict of Interest: The authors declare that the research was conducted in the absence of any commercial or financial relationships that could be construed as a potential conflict of interest.

Publisher's Note: All claims expressed in this article are solely those of the authors and do not necessarily represent those of their affiliated organizations, or those of the publisher, the editors and the reviewers. Any product that may be evaluated in this article, or claim that may be made by its manufacturer, is not guaranteed or endorsed by the publisher.

Copyright (c) 2022 Maaravi, Hameiri and Gur. This is an open-access article distributed under the terms of the Creative Commons Attribution License (CC BY). The use, distribution or reproduction in other forums is permitted, provided the original author(s) and the copyright owner(s) are credited and that the original publication in this journal is cited, in accordance with accepted academic practice. No use, distribution or reproduction is permitted which does not comply with these terms. 